\title{
COMMENTARY: FUNCTIONALITY AFTER THE FONTAN PROCEDURE-PERCEIVED REALITY AND THE PONDERING PRINCE
}

Stephen E. Cyran, MD

$T_{\text {fie }}^{\text {he }}$ he introduction of the Fontan procedure into the field of congenital heart surgery revolutionized the care of patients with single ventricle physiology. Patients experienced an improvement in perceived functionality, as they were free of the chronic cyanosis and ventricular volume loading associated with a long-standing aorta-pulmonary artery shunt. The article titled "Functional Outcome After the Fontan Operation: Factors Influencing Late Morbidity" in this issue of the Journal advances the assessment of perceived functional reality in these patients over a broader scale. ${ }^{1}$ It joins a collection of works by the same group of authors addressing the determinants of surgical success, arrhythmia occurrence, and cognitive development in the post-Fontan patient group. $^{2-4}$ In the present study, Gentles and colleagues carefully catalog the perception of functionality in 363 patients who had undergone some form of Fontan palliation. The majority (91\%) of patients perceived their functionality as "good," being characterized in New York Heart Association Class I or II. For many, their height and weight growth accelerated after conversion of their anatomy to a Fontan circulation from that of shunt physiology. The incidence of morbidity such as protein-losing enteropathy and the need for more than two long-term medications was low, $2.6 \%$ and $19.6 \%$, respectively. At first glance, therefore, the reader may find the perceived functional outcomes reassuring. Yet the authors are correct to emphasize that these positive qualitative indicators need to be tempered by the study's most important finding-that the most sta-

From the Department of Pediatrics, The Milton S. Hershey Medical Center, The Pennsylvania State University, Hershey, Pa.

Requested for publication June 5, 1997; received June 30, 1997; accepted for publication July 3, 1997.

Address for reprints: Stephen E. Cyran, MD, Division of Pediatric Cardiology, Penn State University Children's Hospital, P.O. Box 850, Hershey, PA 17033.

J Thorac Cardiovasc Surg 1997;114:404-5.

Copyright (C) 1997 by Mosby-Year Book, Inc.

$0022-5223 / 97 \$ 5.00+0 \quad \mathbf{1 2 / 1 / 8 4 3 1 4}$ tistically powerful determinant of morbidity was a longer duration of follow-up. Such a finding may, in part, relate to differences in surgical approach over the past 20 years. However, it more likely indicates that an important number of these patients develop significant limitations in activity because of properties intrinsic to the Fontan circulation itself.

This assertion is further emphasized if we view the patients' own reports of functional outcome from the developmental context in which they were obtained. The responses of post-Fontan functionality were collected from three different age groups: (1) preschool children (less than 6 years of age), (2) school-aged children and adolescents (6 to 17 years of age), and (3) adults (18 years of age or greater). In the preschool group, the parents served as the historian and primary assessor of patient functionality. They reported that $69 \%$ of these children were believed to have "no limitation" while $25 \%$ stopped playing "earlier than peers", and only $5.8 \%$ were "unable to partake in 'usual' activity." However, the assessment of functionality by parents in this age group has been shown to correlate poorly with objective measures of cardiovascular performancewith the bias being to a more positive view of their child's performance than that actually measured. ${ }^{5}$ Conversely, this observation engenders concern that the reported number of patients with "no limitation" may be inflated. An additional perceptional difficulty that may result in an exaggerated view of a glowing functional outcome is witnessed in the adult patient group. In this group, only $18.8 \%$ of patients described themselves as having "no limitations." However, when these same patients were asked of what maximal activity they were capable, only $21.4 \%$ could participate in "strenuous activity" and only $11.4 \%$ could perform "heavy housework." This suggests that although perceived functional outcome was good, these patients may have actually been self-limiting their own general activity without conscious awareness.

Given these reservations, the most objective information derives from the school-aged group. It is in this group where patients are requested or re- 
quired to exhibit physical activity in gym class, for example, and as such are unable to self-limit. These patients also serve as their own evaluators, thus minimizing the confounding influence of parental bias. In this context, $65.2 \%$ of patients reported a maximal activity that was below that of peers. Because this relative finding is encumbered by as little interpretive bias as possible, the number is sobering. It coincides with results previously reported by Nir and associates, ${ }^{6}$ which revealed diminished functional performance, on objective exercise stress testing, in a group of 25 patients who had unciergone the Fontan procedure for tricuspid atresia or functional single ventricle.

In summary, the Fontan procedure and its modifications have dramatically altered the functional outcome for patients with single ventricle physiology. Yet the functional information provided by Gentles and colleagues and by others gives the reader pause. On the basis of the present study's results, there would appear to be sufficient rationale to develop further modifications of the Fontan approach and/or novel interventions that would result in improved long-term cardiovascular wellbeing. Furthermore, newer surgical and medical approaches to this challenging circulation must be addressed and evaluated by objective functional measures. Put another way, I am reminded of the story of the prince and his favorite $\log$ in the woods. Legend has it that a young and inquisitive prince would often venture into the forest where he would sit and rest on the same particular log for hours. During this time, he would ponder the world around him, never paying much attention to the log itself. One day, he inadvertently moved the log and observed the underside; it was rotting. He replaced the $\log$ and attempted to re-seat himself but the log never again possessed the same steadiness. Moreover, his perception of the world around him, as well as the $\log$ itself, was changed forever. Gentles and associates have overturned the log of functional outcome after the Fontan procedure: it is not as healthy as one would like. ${ }^{1}$ We must continue to overturn new logs and apply this altered perspective to objectively improve the long-term health of our patients with complex congenital heart disease.

\section{REFERENCES}

1. Gentles TL, Gauvreau K, Mayer JE Jr, et al. Functional outcome after the Fontan operation: factors influencing late morbidity. J Thorac Cardiovasc Surg 1997;114:392-403.

2. Gentles TL, Mayer JE Jr, Gauvreau K, et al. Fontan operation in five hundred consecutive patients: factors influencing carly and late outcome. 1996;114:376-91.

3. Fishberger SB, Wernovsky G, Gentles TL, et al. Factors influencing the development of atrial flutter after the Fontan operation. J Thorac Cardiovasc Surg 1997;113:80-6.

4. Wernovsky G, Stiles KM, Gauvreau K, et al. Cognitive development following the Fontan operation [abstract]. Circulation 1995;92(Suppl):I121.

5. Barber $\mathbf{G}$, et al. Proceedings of the annual meeting of the North American Society of Pediatric Exercise Medicine, 1987.

6. Nir A, Driscoll DJ, Mottram CD, et al. Cardiorespiratory response to exercise after the Fontan operation: a serial study. J Am Coll Cardiol 1993;22:216-20. 